\title{
Medical Students' Experiences of Education with Blended Learning: A Qualitative Study of Perceived Advantages and Challenges
}

\author{
Susanne Nielsen ${ }^{*, 1,2}$, Carina Furåker ${ }^{3}$, Annika Jakobsson $^{1}$ \\ ${ }^{1}$ Institute of Medicine, Department of Public Health and Community Medicine, The Sahlgrenska Academy, University of \\ Gothenburg, Gothenburg, Sweden \\ ${ }^{2}$ Institute of Medicine, Department of Molecular and Clinical Medicine, The Sahlgrenska Academy, University of \\ Gothenburg, Gothenburg, Sweden \\ ${ }^{3}$ Institute of Health and Care Sciences, The Sahlgrenska Academy, University of Gothenburg, Gothenburg, Sweden
}

\begin{abstract}
The aim of the study was to explore medical students' experiences of e-learning and face-to-face meetings (blended learning) with a specific focus on the possibilities of and hindrances to the learning process. A pilot study was conducted with 14 medical students and a main study followed, with 119 medical students participating in three social medicine courses. Of the 119 medical students, 25 took part in a qualitative study evaluating the approach through interviews. These were analysed using manifest content analysis. The findings indicated that blended learning was an appropriate way for medical students to learn about medical insurance issues. The balance between e-learning and face-to-face meetings was satisfactory and the students used a variety of learning strategies when solving authentic patient cases. Some found the pedagogical approach frustrating, since they had to take more responsibility than previously and some were not interested in sharing their knowledge with their fellow students.
\end{abstract}

Keywords: Blended learning, education, medical student, medical insurance

\section{INTRODUCTION}

In recent decades, pedagogical methods have been influenced by both epistemological approaches and students' learning processes $[1,2]$ Technical developments have increased the possibilities for using e-learning in medical education. E-learning has considerable potential to create new and authentic study opportunities for medical students [3], which will provide good preparation for professional practice.

Higher education today does not consist solely of lectures, pure forms of distance learning or face-to-face learning. Instead, mixtures of teaching methods have created new concepts such as 'blended learning' or 'hybrid learning' [4$6]$.

Pedagogical changes have influenced teachers to focus more on developing the learning environment and the educational organization and structure, rather than on creating stimulating content [7]. Different learning styles require different teaching methods, so that each individual can achieve the desired learning outcomes [8-10]. Adults' learning processes imply that students will take responsibility for their learning, while instructors shape students' experiences and guide them through the learning process $[8,11,12]$. The

*Address correspondence to this author at the University of Gothenburg, Sahlgrenska Academy, Institute of medicine, Department of Molecular and Clinical Medicin, Östra Sjukhuset, Smörslottsgatan 1, 41685 Göteborg; Tel: +46709144758; Fax: +4631259254; E-mail: susanne.nielsen@gu.se educational frames, curricula, and resources therefore need to be clear, but unfortunately there is still often a gap between the teacher's instructional goals and what the students really learn. There is, therefore, a need for further research on students' experiences of blended learning and the effectiveness of teaching methods [9, 12].

E-learning as a pedagogical method is not new. Blended learning, on the other hand, is still under development and may prove to combine the most useful aspects of e-learning and traditional educational methods [13]. It can involve everything from a simple combination of face-to-face education and distance learning to a more complex form of education, including various forms of interactivity [14]. The major challenge for educators is to find the right mix (blend) of elearning and face-to-face learning for each individual [ 15 , 16]. Instead of comparing e-learning and campus-based education, the focus should be on finding out when e-learning can be used, how it can be used effectively, and what strengths and weaknesses may exist in e-learning in medical education [15]. Research studies suggest that a combination of teaching methods, such as on-line discussions and face-toface meetings/seminars, appear to develop students' critical thinking in higher education [17].

Swedish medical education strives to prepare students for their future professional lives [18]. Therefore, it includes opportunities for students to work independently and to practise decision-making based on complex situations [19]. Changes of policy on the sick leave process and new tech- 
nology-driven support systems have affected the clinical work of doctors and require the development of additional knowledge and skills among medical students [20]. Learning about sick leave processes is complex and doctors need upto-date knowledge and skills to be able to deal with, for example, the medical insurance system and policies. Knowledge of how to issue a medical certificate is not sufficient [21]. Pedagogical methods such as e-learning combined with face-to-face seminars (blended learning) might be a suitable way to learn about these areas. Hence, blended learning could be an appropriate pedagogical method for this part of medical education. It could even be close to praxis, that is, authentic education.

The research setting was a medical insurance course in social medicine. This course previously consisted of approximately 6-8 hours of traditional lectures, along with a visit to the Swedish Social Insurance Agency, where the students met doctors and experts in social insurance. It was therefore necessary tomodify and developthis traditional course into a blended learning course that aimed to provide the students with an authenticlearning environment.

The use of blended learning in medical education is not unusual, but knowledge of when and how blended learning can and should be used is still lacking.It is important to identify possibilities for and hindrances to using blended learning in medical education. There is also a need for studies that focus on how the mix (blend) between face-to face meetings and e-learning stimulates students' learning processes [15]. One challenge in medical education is to apply appropriate teaching methods so that the students learn how to use the authentic Internet tools they will later use in their professional lives [9]. Consequently, there is a need for studies that search for strengths and limitations in both the learning environment and students' learning processes during courses with blended learning. The aim of this study was therefore to explore medical students' experiences of e-learning and faceto-face meetings (blended learning), with a specific focus on the possibilities and hindrances in the learning process.

\section{MATERIALS AND METHODOLOGY}

\section{Setting and Procedure}

The project took place in a Swedish university during 2009 and 2010 and started with a pilot study. The pilot study used voluntary participants from a course in social medicine. The main study recruited students from three compulsory social medicine courses (Table 1). The purpose of the pilot study was to develop and evaluate the structure and content of the course, including the e-learning platform.

In both the pilot and the main study, the teaching material was available on an e-learning platform that was also used for communication between students and teachers. The underlying idea was to provide opportunities to learn the required skills and offer the students an authentic situation in which to use their problem-solving skills, which would also be a realistic way in which to prepare them for their future profession, as they would use authentic technology and patient situations. The course structure intended to stimulate the students' ability to reflect and work independently while learning how to handle the sick leave process. The teaching material consisted of documents that included Internet links to sources aimed at helping the students to solve three patient cases of varying complexity in order to issue a medical certificate. The course also included a seminar at the Social Insurance Agency.This face-to-face meeting was intended to give the students the opportunity to discuss medical insurance issues with representatives from the local insurance office together with medical professionals and teachers. After evaluating the pilot study, a special face-to-face seminar was added in which the students could discuss ethics and their professional role with experienced medical practitioners.

\section{PILOT STUDY}

\section{Participants and Data Collection}

All 44 students on a social medicine course were invited to participate voluntarily in the pilot study and 20 agreed to do so. Within a month of the end of the pilot study, interviews were undertaken with the participants about their experiences of the course structure and content. Six could not be reached to determine a time for the interview, but 14 were interviewed by telephone. No major changes in the study material were made as a result. However, the students considered the assignments too extensive for the learning outcomes, so the number of assignments was reduced from four to three and a face-to-face session was substituted for the fourth.

Table 1. Overview of All Teaching Occasions

\begin{tabular}{|l|c|c|}
\hline & Students (n) & Interviews (n) \\
\hline \hline Pilot course & 20 & 14 \\
\hline Teaching course no. 2 & 35 & 4 \\
\hline Teaching course no. 3 & 47 & 8 \\
\hline Teaching course no. 4 & 37 & 13 \\
\hline Total & 139 & 39 \\
\hline
\end{tabular}




\section{MAIN STUDY}

\section{Participants and Data Collection}

The implementation of the main study started immediately after the pilot study had ended. The main study used 119 medical students on three compulsory courses. A qualitative methodology with interviews was applied to collect data. To recruit interview participants, the first author visited the students after each course and informed them about the study, that participation was voluntary, and that varied experiences of the courses were sought. Interested students were then given the opportunity to sign up to be contacted for an interview. Initially, 30 students reported an interest in participating; four of these could not be reached and one

declined to participate. In the end, 25 individual qualitative interviews were conducted with 12 female and 13 male students, whose age ranged between 23 and 48 years old. Four of the interviews were done by telephone and the others face-to-face in the students' homes, at the university, or in hospitals. All of the interviews were audio-recorded, transcribed verbatim and numbered. Each interview lasted between 25 and 55 minutes and all were conducted within one month of the end of the course.

\section{Ethical Considerations}

According to Swedish legislation, ethical permission from an Ethics Committee is not needed for this kind of research. The students were given information about the purpose of the study, the voluntary nature of their participation, and the fact that they could terminate their participation at any time. The interview material was treated with confidentiality [22].

\section{Analysis}

The interviews were analysed through qualitative manifest content analysis [23]. First, the texts were read several times to get an overview of the material. Next, a search was made for words and meanings linked to the aim of the study

Table 2. The Analytical Process for the Theme 'Knowledge Development'

\begin{tabular}{|c|c|c|c|c|}
\hline Meaning Units & Condensed Text & Meaning Code & Subtheme & Theme \\
\hline $\begin{array}{l}\text { I think we got great feedback this time, } \\
\text { by the teacher. It was nice because it is } \\
\text { seldom that you have a feeling... it felt } \\
\text { like they had taken an active interest } \\
\text { and really tried to provide constructive } \\
\text { criticism } \\
\text { (I 19) }\end{array}$ & $\begin{array}{l}\text { Great feedback this time } \\
\text { Not used to being seen as an individual } \\
\text { student and getting individual feedback } \\
\text { Teachers took an active interest and } \\
\text { gave constructive criticism }\end{array}$ & $\begin{array}{l}\text { Exceeding expecta- } \\
\text { tions }\end{array}$ & Feedback & $\begin{array}{l}\text { Knowledge devel- } \\
\text { opment }\end{array}$ \\
\hline
\end{tabular}

Table 3. The Analytical Process for the Theme 'Conditions for Learning'

\begin{tabular}{|l|l|l|l|l|}
\hline \multicolumn{1}{|c|}{ Meaning Units } & \multicolumn{1}{|c|}{ Condensed text } & \multicolumn{1}{|c|}{ Meaning Code } & \multicolumn{1}{c|}{ Subtheme } & \multicolumn{1}{c|}{ Theme } \\
\hline \hline $\begin{array}{l}\text { We have very few writing assign- } \\
\text { ments, we almost have no take-home } \\
\text { examinations at all, it's like... It's sit } \\
\text { an examination or practical tests or } \\
\text { oral tests }\end{array}$ & $\begin{array}{l}\text { Few writing assignments } \\
\text { Little experience of take-home examina- } \\
\text { tions }\end{array}$ & $\begin{array}{l}\text { Lack of experience } \\
\text { in writing }\end{array}$ & Internal frames & $\begin{array}{l}\text { Conditions for } \\
\text { learning }\end{array}$ \\
(I 14) & & & & \\
\hline
\end{tabular}

Table 4. Overview of Themes and Subthemes

\begin{tabular}{|l|c|c|}
\hline \multicolumn{1}{|c|}{ Themes } & Conditions for Learning & Knowledge Development \\
\hline \hline Subthemes & Independence & Teachers' response \\
\hline & Communication through the e-learning platform & Strategies for learning \\
\hline & Internal frames & Sharing knowledge \\
\hline & External frames & Meeting face-to-face \\
\hline
\end{tabular}


that formed 'meaning units'. The meaning units were classified depending on whether participants expressed positive or negative views about blended learning. They were then condensed and coded (Tables $\mathbf{2}$ and $\mathbf{3}$ ). Finally, differences and similarities were sought among the codes and they were grouped into nine subthemes and two themes. Researcher triangulation was used to facilitate validation during the analyses. The three authors analysed the transcripts individually, searched for meaning units and met to discuss the codes to counteract any inadequacies [24].

\section{Results}

The first theme, conditions for learning, included four subthemes: independence, communication through the elearning platform, internal frames, and external frames. The second theme, knowledge development, included five subthemes: teacher's response, strategies for learning, incentives for learning, sharing knowledge, and meeting face-to-face (Table 4).

\section{CONDITIONS FOR LEARNING}

\section{Independence}

E-learning motivated the students and gave them flexibility, allowing them to study in their own time and at their own pace. This flexibility was described as a positive factor, especially for those with families or children. However, the need for self-discipline was problematic for some of the students.

\section{Communication through the e-learning platform}

The teachers' availability and prompt response to questions satisfied the students and were important factors for their learning. However, the students also said that they missed the face-to face contact with the teachers, especially when they had spontaneous questions:

... they were very engaged, so ... you got good answers but ... hmm //...// I think that you will get more out of it if you talk. (I 1)

One hindrance to communication was that the students hesitated to ask questions because they did not want to bother the teachers. Another factor that limited communication was the students' lack of ability to formulate written questions that would elicit a deeper communication from the teachers.

\section{Internal frames}

The students had mixed feelings about exposing their assignments to each other. Some did not consider it to be an issue, but others talked about the risk of violation of integrity. They also said that it was unusual to expose their identity, as in traditional education, examinations were anonymous. The students spoke about their own capacity to determine their study efforts, expressing concerns about how much time they should spend on each assignment, and what type and depth of knowledge they were supposed to acquire. The students were not used to being given problem-solving assignments to resolve by themselves and preferred the teacher to tell them what was right and what was wrong:

I think that the problem is that we don't do any of that during the medical education/.../ and now, I haven't written anything to hand in, in about four and a half years, so I think that it is a little, it's unfamiliar and especially when you're supposed to discuss an ethical problem. But I think that it's wise really to have to do that, really. (I 18)

With only a few exceptions, knowing how to work with computers was not a problem for the students. Instead, their difficulties were connected to the new way of learning as they lacked experience of e-learning and its tools. However, with time, they became increasingly skilled in their use. This provided a good foundation for the future, even if they did not feel completely secure and knowledgeable about the more complex cases.

\section{External frames}

The students considered being able to plan their study time to be important for their learning. Although they thought the medical insurance course was well planned, they felt that as a whole, it was overloaded, which caused problems with time management. Another aspect that affected the students' learning was their access to computers. Courses that included blended learning required the availability of a computer with an Internet connection and some students saw this requirement as unfair, as it could influence their conditions for learning. In general, the students thought that the study material was relevant and the instructions were clearly expressed and easy to follow. The study material contained links to relevant Internet sites, and the students appreciated this, except when the links did not work, as this was irritating and frustrating. Although technical flaws were not generally major problems, there was an issue with late login information from the National Insurance Office Internet site. However, the students solved this problem by borrowing login information from fellow students.

The mix of different pedagogical methods, including elearning, face-to-face seminars, and visits to the local insurance office, was described as a very positive blend:

I think that it is better to do it in e-learning than in lectures, and all should sit and write their individual doctor's certificates, I don't believe that you can // ... // I don't think that you will gain the same broadness in your knowledge, if you only had had the lecture on... ehh, medical insurance. (I 7)

E-learning stimulated the students to draw conclusions and to make their own decisions. The face-to-face meetings provided opportunities to discuss and reflect on ethical dilemmas and the insurance system in general. This, taken as a whole, helped them to be more self-directed.

\section{KNOWLEDGE DEVELOPMENT}

\section{Teacher's Response}

The students considered that individual feedback from teachers was important for knowledge development and con- 
firmation. Comments from teachers were experienced as constructive and added new perspectives. The students also described the feedback and comments as unusually rich and useful:

It was good, and I think that we got good feedback this time as well, from the teacher. That was fun, because it is rare that, that you feel that they get themselves properly involved, and really try to give constructive criticism. (I 19)

The students emphasized that feedback had a 'best before date' and mentioned the need for prompt feedback before the next course began. After the course had ended, they would not have time to reflect on or even to read the teacher's comments.General feedback was less likely to be read than individual feedback, and when it was read, it was only skimmed. The reason for this was the difficulty of relating general feedback to individual assignments.

\section{Strategies for Learning}

The students employed five different learning strategies. The first was to demarcate the learning by putting a limit on what it was reasonable to learn during the course, as opposed to what they could learn later when they started to work as medical practitioners. Another strategy was to understand and see the context. Their focus here was not on facts or details, but rather on how to understand and get a general idea of what would be useful knowledge for the assignments:

And it is that somehow - what a university education is all about, to sort out and prioritize what to read..., and not read everything, and remember everything backwards, like you could do earlier, without having to sort out what's important but, I think it was that, I mean the texts were about so much more than writing these opinion reports. (I 18)

A contributing factor to this strategy was that the students felt responsible for their own learning and wanted to understand the recommendations from the Swedish National Board to allow them to make decisions. The third learning strategy used by the students was to grasp the initiative themselves. Some felt the structure allowed this, but others felt "forced" to take responsibility for seeking the knowledge that would enable them to solve their assignments. These ways of learning led them to apply their knowledge:

....then you had to find the information yourself and click on the next link, like, it was a direct communication with the body of information and yourself, and somewhere out there you would find the answer, it wasn't like in a normal lecture when you're fed with what's important, yap, yap, yap, and this and that... (I 25)

Another learning strategy was trial and error, which meant that they did not use a specific strategy at all. They went back and forth in the study material, searching for information without any particular focus, and visiting different Internet links in case they provided any information relevant to the assignment. The final learning strategy was a 'cue seeker' approach. These students tried to guess what they would need to know to pass the examination, or what the teacher expected them to write. They used the size of the form boxes in the medical certificate to help them decide how much text they needed to write:

Because, that's how it works, you read what you need to know to pass the exam and if you want people to read more, yes, then you need to say that it's broader than that. (I 21)

\section{Incentives for Learning}

The students felt that the course structure, the study material, and the assignments provided a realistic approach to the topic. They saw the benefits of the setup of the e-learning platform, which promoted the skills they would need as doctors:

As a doctor you will have access to books, you will have access to the Internet, and then it's not about remembering everything - it's more about where do I find the information, and how do I assimilate what I can read and.../.../, I would have liked more take-home exams, I would. (I 14)

There were also students whose incentives for learning were based on the fact that the assignments were mandatory.These particular students generally felt that this method of learning took a great deal of time, and could not see its usefulness:

...there was a deadline for submitting a certificate ... otherwise I would have postponed it/.../to be forced to submit something ... then I cannot postpone it ... then I have to learn it. (I 15)

\section{Sharing Knowledge}

The students were given the opportunity to read each other's assignments, which caused some ambivalence. It was a benefit to compare their work to that of others and confirm that they were on the right track. They could also see variations in reasoning. This approach gave them more confidence in developing their own assignments. Some students looked at their fellow students' coursework before they did their own, whereas others did their own work first. Some did not realize that they could see each other's coursework until after they had submitted their work.Regardless of when the students read their peers' assignments, they carefully chose with whom to compare themselves. They preferred to compare their work to that of a fellow student whom they thought had first-rate knowledge.Some students said that they were inspired by the work of their fellow students, whereas others felt that there was a risk of plagiarism if they read someone else's work:

It must feel a little bit peculiar if you don't have, if you say ok, now I have produced and worked hard here and then it's completely open ... what I have done, someone can just copy, and more like ... what, what do I gain for this like.../. (I 11)

\section{Meeting Face-to-Face}

Even though most students worked on their assignments independently, some chose to work together face-to-face, which allowed them to discuss their work with their peers. 
They did this even though they were not sure if they were allowed to do the assignments together:

It is very important to hear what the others think and sometimes just to confirm that I think like the rest/.../ some of that I could compensate for when I could look at the others' reports but I still didn't know ... the reasoning behind their answers. (I 6)

\section{DISCUSSION}

The findings indicate that blended learning is a suitable way for medical students to learn to handle medical insurance issues. The balance between e-learning and face-to-face meetings also seemed to be satisfactory.

The intentions behind the pedagogical approach were to encourage more activities among the students and to make the education as authentic as possible. The students had the opportunity to use several different learning strategies. However, some of the students found blended learning frustrating as a pedagogical approach: they were not accustomed to taking responsibility for what and how to learn, nor could some select what to focus on, and this caused stress and concern. Even though they said that they had obtained knowledge and skills that would be useful in their future careers, they still wanted the teachers to give them a key to what constitutes important knowledge, like a recipe book. This, they felt, would support them in their professional careers, in finding and applyingtimely and relevant knowledge about medical insurance.One reason why the students wished to receive core knowledge from the teachers could have been that they had an individual examination at the end of the course. The traditional examination style demands the ability to memorize and reproduce facts [25]. The examination design in this course might therefore create uncertainty among students about what kind of knowledge to focus on. Marton et al. [26] identified that students' achievements are related to several conditions in the study environment. The examination designaffectshow and what studentslearn to a great extent.The content of the exam may showthe 'true' expected learning outcomes of a course. According to Marton et al. [26], students often try to find out which skillsareimportanttolearnand adapttheirlearningto what theyare expected to know; that is, they are cue seekers. Whether the students appreciated blended learning or not might also be a consequence of the learning style they had adopted. A previous study has shown that students who are positive about e-learning tend to use a deep approach to learning and those who are negative tend to use a surface approach [27].

One of the challenges of using blended learning identified by the students was the difficulty of communicating with the teachers through the e-learning platform. This is in line with the findings of other researchers [28]. Another hindrance the students experienced was difficulty in understanding and writing the kind of assignments required. The reason for these difficulties could be the students' lack of familiarity with communicating through written text. Their difficulties with written communication show the importance of using patient cases of varying complexity in educational settings, to mimic the demands of their future work. The use of information technology requires the ability to summarize, condense and critically review written texts [2,29]. The reported lack of experience of assessed written assignments shows that it could be beneficial to apply teaching methods that stimulate students to seek knowledge, make decisions and write essays. These findings support those of Howatson Jones [30] that technological systems such as e-learning need to be combined with facilitators and tutors collaborating with learners on an equal level to achieve reflexive learning.

The purpose of open forums on e-learning platforms was to give the students an opportunity to learn from and see variations in each other's coursework. The students in this study said that they felt uncomfortable with open forums because they did not want to expose themselves to their fellow students, in case they might be thought unintelligent, which is consistent with other studies [31]. Their lack of willingness to share knowledge and assignments with others was also due to the suspicion that their fellow students could take advantage of or benefit from their writings. This was a sensitive issue during the interviews, and can be related to the students' high ambitions, as well as the competition for high grades.

Teachers need to be aware of this lack of willingness to share knowledge and assignments when starting courses and using open forums, as they may need to provide additional information, for example, about the purpose of using open forums. It is possible that this might not have been clearly explained in the study, and that if the impact of sharing knowledge had been clarified, the results might have been different. The number of open forums on the e-learning platform, where students could see each other's assignments, was reduced after the pilot study. In the third and fourth courses, only one open forum was available. This change was made because the students highlighted the possibility of cheating. In our view, however, open forumsareimportantforstudents' knowledge development and therefore clear information about the purpose ofopenforums must be given at the start of the course. The question arises whether medical students are more like lyto believe that their fellow studentscheat than other students.

\section{STUDY STRENGTHS AND LIMITATIONS}

The procedure whereby the students were recruited from different courses could lead to concerns about selection bias and what impact this could have on the results. It was essential that participation in the study was on a voluntary basis, and that a variation of statements was obtained. Since the background of all 139 students was similar in terms of marks and school type, the selection focused on variation concerning age, sex and positive and negative experiences of using blended learning. The wide age range (23-48) and the even distribution of male and female students that was achieved, strengthen the trustworthiness of the study, as does the variation in experiences on the course, that included both positive and negative views.

The number of students who signed up to participate varied between the groups in the main study. The smallest number of interviewees was recruited from the second teaching course due to the summer break. Additional possible barriers to participation were that the students continued to the next course immediately, and usually have heavy workloads, so were not prepared to commit to additional work. In our view, a particular strength of this study was that the interviews generated rich data for the analysis. Furthermore, the participants were recruited from four different courses, which allowed variation in the data and ensured that the results were 
based on views about several teaching courses. Other strengths were that the authors are not involved in medical education, and that all the interviews were conducted within a month of the end of the courses, to ensure that the limitations of memory would not influence the outcomes of the study. The study also had some limitations. One was that four of the interviews were conducted by telephone. These interviews were shorter, due to the distracting environment and the fact that some follow-up questions were not asked. In addition, not all of the planned face-to-face seminars were carried out. Nonetheless, there is no evidence to suggest that the outcomes would have been different if all the seminars had been held as planned.

\section{CONCLUSION}

This study indicates that medical students used five different learning strategies when learning about medical insurance issues, including trial and error and cue seeker strategies. Blended learning increased the opportunities for students to take more responsibility for their learning, but some students still wanted the teachers to decide what wasim portant. Getting individual feedback was perceived asim portant for learning.Open forums require teacher's attention to that students may not be interested in sharing their knowledge with fellow students unless additional information about the purpose is provided.

\section{COMPETING INTEREST}

We have no competing interests to declare in relation to this manuscript

\section{ACKNOWLEDGEMENTS}

We would like to thanktheInsurance Fund in Sweden and thePedagogical Development and Interactive Learning (PIL) at the University of Gothenburg for their financial contributions tothe study.

\section{REFERENCES}

[1] Dysthe O, Editor. Dialogue, interaction and learning. Lund: Studentlitteratur Ed, 2001.

[2] Säljö R. Learning in practice: a sociocultural perspective. Stockholm: Bokfölaget Prisma 2000.

[3] Ruiz JG, Mintzer MJ, Leipzig RM. The impact of E-learning in medical education. Acad Med 2006; 81(3): 207-12.

[4] Ellis RA, Goodyear P, O'Hara A, Prosser M. The university student experience of face-to-face and online discussions: coherence, reflection and meaning. Res Learn Technol 2007; 15(1): 83-97.

[5] Olapiriyakul K, Scher JM. A guide to establishing hybrid learning courses: employing information technology to create a new learning experience, and a case study. Internet Higher Educ 2006; 9(4): 287-301.

[6] Rovai AP, Jordan HM. Blended learning and sense of community: a comparative analysis with traditional and fully online graduate courses. Int Rev Res Open Distance Learn 2004; 5(2).

[7] Laurillard D. Rethinking university teaching: a conversational framework for the effective use of learning technologies. London: Routledge Falmer 2002.
[8] Cercone K. Characteristics of adult learners with implications for online learning design. AACE J 2008; 16(2): 137-59.

[9] Wong G, Greenhalgh T, Pawson R. Internet-based medical education: a realist review of what works, for whom and in what circumstances. BMC Med Educ 2010; 10(1).

[10] Segerstad HH, Klasson A, Tebelius U. Adult education: to stage adult learning. Lund: Studentlitteratur 2007.

[11] Maltén A. Teaching: A multifaceted challenge. Lund: Studentlitteratur 2003.

[12] Ramsden P. Learning to teach in higher education. 5th ed. Cornwall: TJ International Ltd. 2003.

[13] Akkoyunlu B, Soylu MY. A study of students' perceptions in a blended learning environment based on different learning styles. Educ Technol Soc 2008; 11(1): 183-93.

[14] Garrison DR, Kanuka H. Blended learning: uncovering its transformative potential in higher education. Internet Higher Educ. 2004; 7(2): 95-105.

[15] Cook DA. The failure of e-learning research to inform educational practice, and what we can do about it. Med Teach 2009; 31(2): $158-62$.

[16] Gormley G, Collins K, Boohan M, Bickle I, Stevenson M. Is there a place for e-learning in clinical skills? A survey of undergraduate medical students' experiences and attitudes. Med Teach 2009; 31(1): e6-e12.

[17] Guiller J, Durndell A, Ross A. Peer interaction and critical thinking: face-to-face or online discussion? Learn Instruct 2008; 18(2): 187-200.

[18] SFS. Higher Education Ordinance. In: research MoEa, Editor. Stockholm: Ministry of Education and Research 1993.

[19] Nilsson MS, Pilhammar E. Professional approaches in clinical judgements among senior and junior doctors: implications for medical education. BMC Med Educ 2009; 9(1).

[20] The National Board of Health and Welfare. Medical Insurance decisions: guidance for Sick leave 2007.

[21] The National Board of Health and Welfare. Monitoring and improvement of insurance medical decision support: welfare and social insurance joint progress report on developments in 2008 National Board of Health and Welfare 2009.

[22] Swedish Statute Book. The act concerning ethical review of research involving humans. In: Research MoEa,. Stockholm 2003.

[23] Graneheim UH, Lundman B. Qualitative content analysis in nursing research: concepts, procedures and measures to achieve trustworthiness. Nurse Educ Today 2004; 24(2): 105-12.

[24] Sim J, Sharp K. A critical appraisal of the role of triangulation in nursing research. Int J Nurs Stud 1998; 35(1-2): 23-31.

[25] Lander R. Student opinion on the biomedical block. Survey and interview data on the first four semesters at the Sahlgrenska Academy's medical school. Gotheburg: Department for Education, Unit for Individual, Culture and Society 1997.

[26] Marton F. Learning and outlook on the world: a book about the human being as a student. Stockholm: Prisma 1999.

[27] Nielsen S, Plos K, Furåker C, Jakobsson A. Authentic situations motivate medical students for dealing with medical insurance issues. Creat Educ 2012; 3(1): 120-125.

[28] Lewin LO, Singh M, Bateman BL, Glover PB. Improving education in primary care: development of an online curriculum using the blended learning model. BMC Med Educ 2009; 9(1).

[29] Salmon G. E-moderating: the key to teaching and learning online. London: Kogan Page Limited 2004.

[30] Howatson-Jones L. Exploring nurses' learning. Eur J Res Educ Learn Adults 2012; 3(1): 43-57.

[31] Carroll C, Booth A, Papaioannou D, Sutton A, Wong R. UK health-care professionals' experience of on-line learning techniques: a systematic review of qualitative data. J Contin Educ Health Prof 2009; 29(4): 235-41.

This is an open access article licensed under the terms of the Creative Commons Attribution Non-Commercial License (http://creativecommons.org/licenses/by-nc/3.0/) which permits unrestricted, non-commercial use, distribution and reproduction in any medium, provided the work is properly cited. 